\title{
Characterization of natural adsorbent material for heavy metal removal in a petrochemical site contamination
}

\author{
F. Bianchi ${ }^{1}$, C. Farao $^{2}, \underline{\text { M. Maretto }}^{3}$, M. Petrangeli Papini ${ }^{4}$ and R. Vignola ${ }^{5}$ \\ ${ }^{1}$ Dipartimento di Chimica,Università Sapienza di Roma, Rome, Italy, federica.blanchi@libero.it \\ ${ }^{2}$ Dipartimento di Chimica,Università Sapienza di Roma, Rome, Italy, carmela.farao@uniroma1.it \\ ${ }^{3}$ Dipartimento di Chimica,Università Sapienza di Roma, Rome, Italy, moreno.m@uniroma1.it \\ ${ }^{4}$ Dipartimento di Chimica,Università Sapienza di Roma, Rome, Italy, marco.petrangelipapini@uniroma1.it \\ ${ }^{5}$ Dipartimento di Chimica,Università Sapienza di Roma, Rome, Italy, rodolfo.vignola@yahoo.it
}

\begin{abstract}
Despite of over 25 years of intensive technological efforts, sub-surface environment cleanup still remains a challenge, especially in case of highly contaminated sites. In this context, ion exchanger technologies could provide simple and effective solutions for heavy metal removal in water treatment. The challenge is finding exchanger able to operate in extreme natural environments or in situations involving natural interfering species such as inorganic ions. In this paper we exam the use of natural zeolites as versatile exchanger for environmental protection of coastal refinery's groundwater against pollution of $\mathrm{Ni}, \mathrm{Cd}, \mathrm{Pb}$. The influence of particle diameter on clinoptilolite performances toward heavy metal removal is studied. Also, we evaluate the exchanger activities in condition of high ionic strength, commonly present in groundwater located under coastal petrol industries. The obtained results confirmed that ion exchangers could provide an effective solutions for remediation in complex environmental conditions.
\end{abstract}

Keywords: Heavy metal removal, adsorption process, ion exchange, diameter particles.

\section{Introduction}

In a worldwide context where in some areas of the earth the lack of drinkable and irrigation water is endemic, it is necessary the recovery and remediation of petrochemical contaminated waters, to not impoverish global water resources. The pollution of these waters doesn't involve only high concentrations of organic compounds but also the presence of heavy metals, that, even if at trace levels, determines residual concentrations above the allowed limits. Today the most commonly used techniques to remove heavy metals from water can be classified into chemical processes, such as flocculation and precipitation, and chemical-physical processes, such as the adsorption on activated carbon.

Nowadays the use of some natural and synthetic adsorbent materials, able to impound heavy metals from waters with selectivity higher than activated carbon, is growing up.

In this work we consider kinetic and thermodynamic aspects of the adsorption of $\mathrm{Pb}^{2+}, \mathrm{Cd}^{2+}$ and $\mathrm{Ni}^{2+}$ on natural materials such as clinoptilolite. These elements are present at trace levels in crude oil (Uzoekwe and Oghosanine, 2011) and are toxic for human people and environment too. In particular, the influence of the clinoptilolite particle sizes on both the adsorption rate and the maximum absorbable amount is studied.

The removal performances of zeolite under growing ionic strength conditions, up to simulate the seawater levels, is also examined. This last aspect has to be deepened considering the huge seawater consumption by the petrochemical industries for extracting and refining crude oil and the diffuse presence along coasts of this plants, that often causes the contamination of groundwaters.

\section{Materials and Method}

Clinoptilolite was washed with distilled water and kept on stirring for 6 hours in a $2 \mathrm{M} \mathrm{NaCl}$ solution. After this step the material was rinsed with distilled water and kept again on stirring with $\mathrm{NaCl} 2 \mathrm{M}$. This procedure is necessary to ensure that all the exchange sites are saturated with $\mathrm{Na}^{+}$, thus allowing a higher homogeneity during the adsorption process. Subsequently, the zeolite underwent a grinding process and a riddling in the following size classes : 63-125 $\mu \mathrm{m}, 125-200 \mu \mathrm{m}, 200-500$ $\mu \mathrm{m}$ and 500-1000 $\mu \mathrm{m}$. 
The cationic exchange capacity of the clinoptilolite was determined with the barium sulphate method (ISO 11260 , 1994). The characterization studies were conducted using water solutions of $\mathrm{NiCl}_{2}, \mathrm{~Pb}\left(\mathrm{NO}_{3}\right)_{2}$, $\mathrm{Cd}\left(\mathrm{NO}_{3}\right)_{2}$ (Sigma Aldrich®). All the solid materials were weighted by Gibertini E42 weigh-scale.

The experimental tests to evaluate the times of attainment of adsorption equilibria (kinetics studies) were conducted in batch reactors. In these tests $1 \mathrm{~L}$ of solution at $1 \mathrm{mg} / \mathrm{L}$ of each metal ion and $1 \mathrm{~g}$ of clinoptilolite particles were maintained under magnetic stirring; $10 \mathrm{~mL}$ of the solution were sampled at fixed times, filtered (cellulose nitrate; $0,43 \mu \mathrm{m}$ ) and analyzed by optical emission inductively coupled plasma (ICP-OES; Varian Vista MPX). The study of the adsorption isotherms was conducted under rotative stirrer ( $24 \mathrm{~h}$; FALC F205) to avoid the mechanical break-up of particles. The isotherms were carried out at variable ionic strength $\left(\mathrm{NaNO}_{3}\right.$ ranging from $10^{-3} \mathrm{M}$ to $0,6 \mathrm{M}$ ) by varying initial concentrations of metal solutions $(5 \div 50 \mathrm{mg} / \mathrm{L})$ and keeping fixed the adsorbent solid amount $(1 \mathrm{~g} / \mathrm{L})$.

Tests were repeated for each particle size class.

\section{Result and Discussion}

Firstly we evaluated the equilibrium attainment time of the adsorption process on each dimensional fraction of clinoptilolite particles. Figure 1 shows the variation of $\mathrm{Cd}^{2+}$ (left panel) and $\mathrm{Pb}^{2+}$ (right panel) solution concentration as a function of the contact time. Unexpectedly, only a slightly dependence of kinetics adsorption of these metals from the particle diameter was observed. Assuming a pseudo-first order rate equation for ion exchange of $\mathrm{Cd}$ and $\mathrm{Pb}$, we calculated the kinetic constants. Figure 2 shows graphs of kinetic constant versus the decimal logarithmic of the difference between the upper and lower value of diameter particles for each size range.
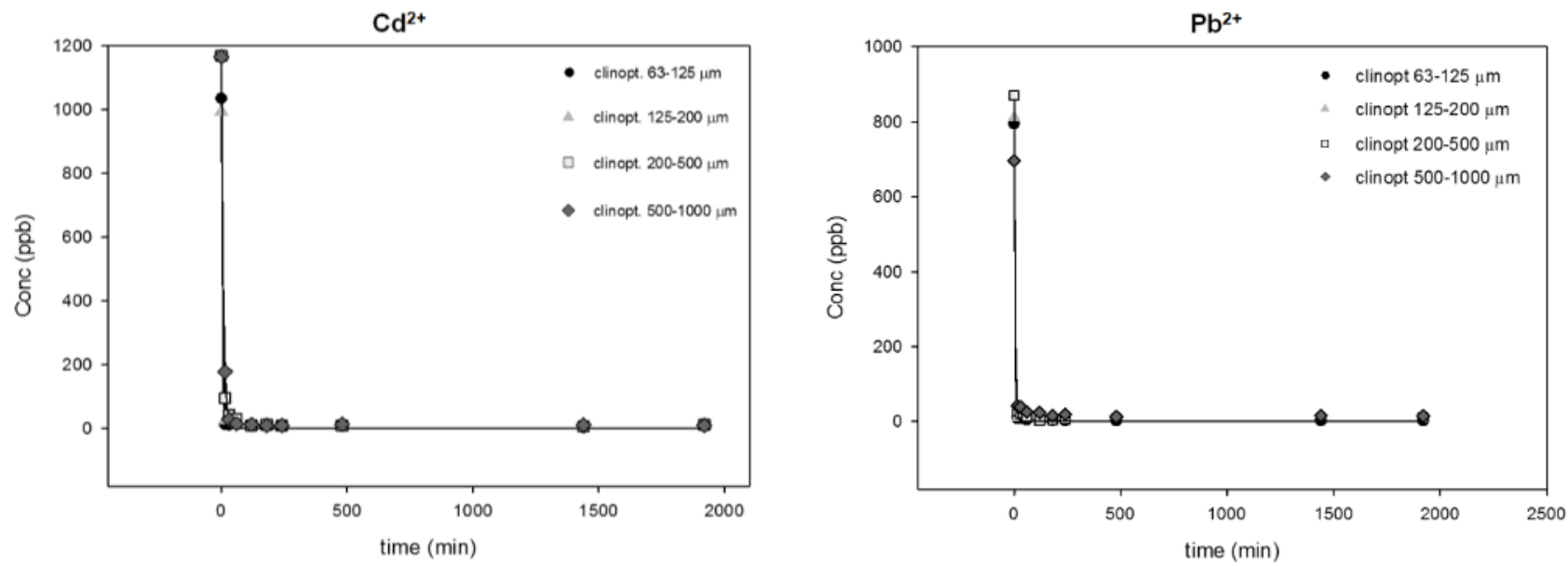

Fig.1 Kinetic study for equilibrium atteinement time of adsorption of $\mathrm{Cd}^{2+}$ and $\mathrm{Pb}^{2+}$ onto cinoptilolite
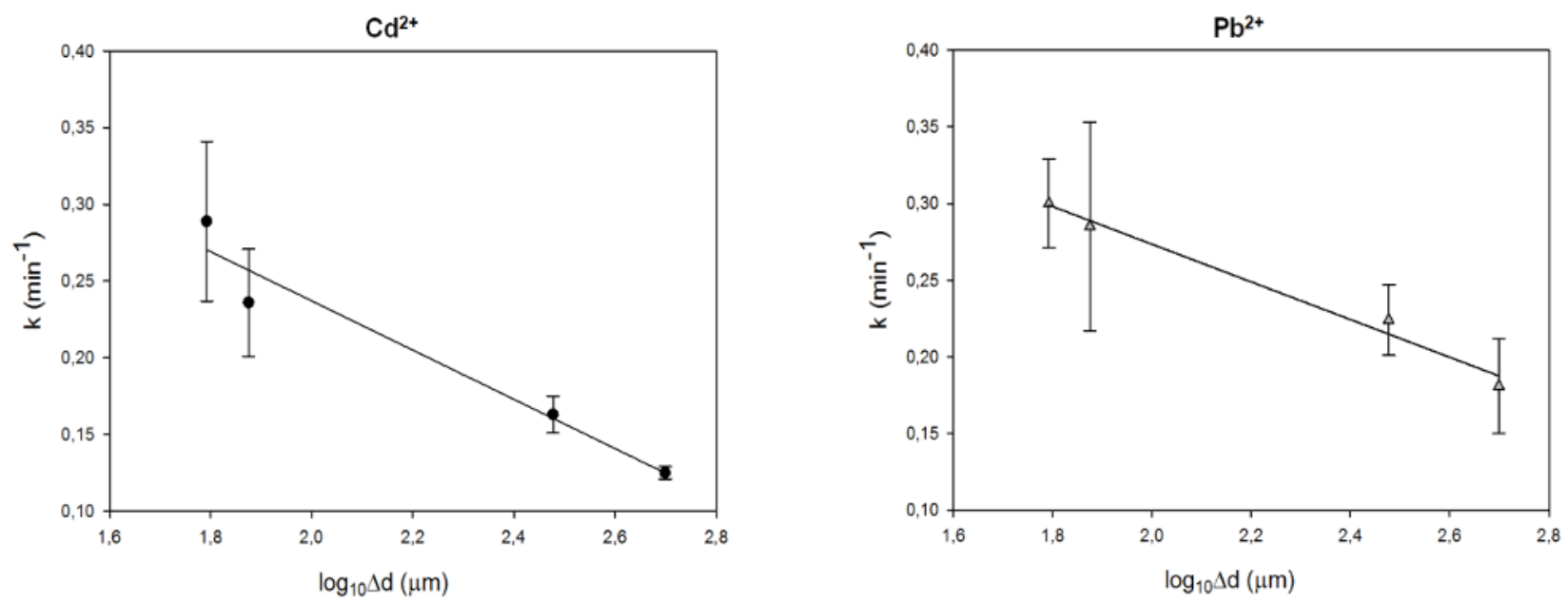

Fig.2 Linear dependence of $\mathrm{Cd}^{2+}$ and $\mathrm{Pb}^{2+}$ adsorption kinetic constant from particles size of clinoptilolite 

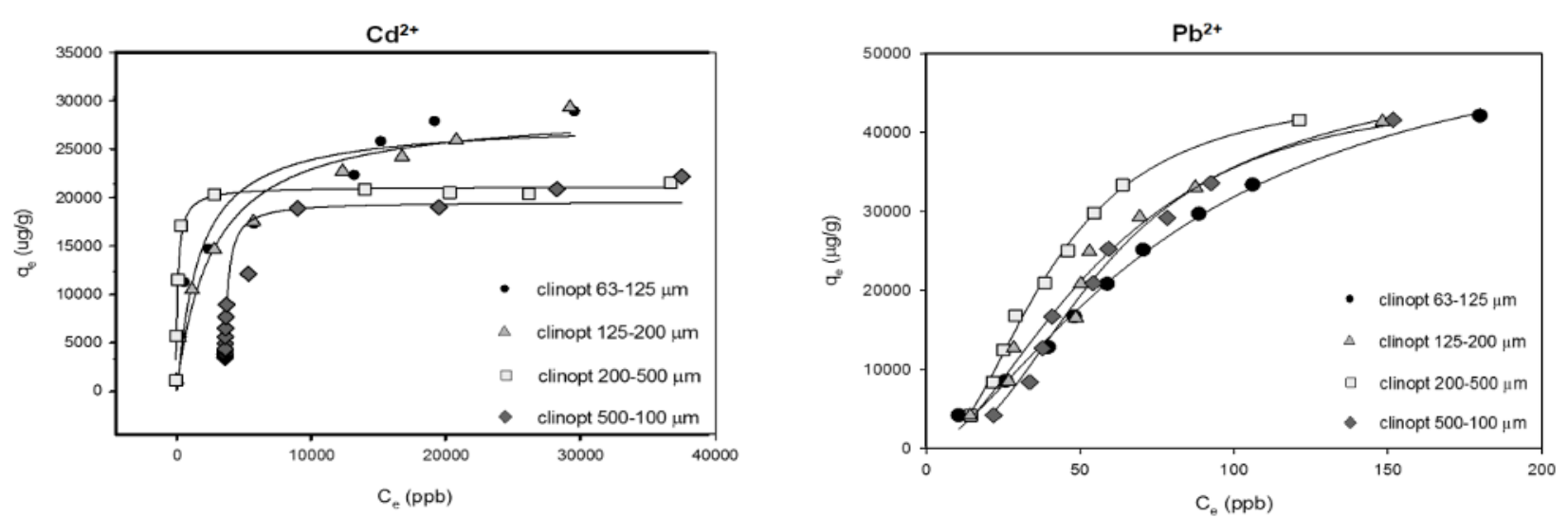

Fig.3 Adsorption isotherm of $\mathrm{Cd}^{2+}$ and $\mathrm{Pb}^{2+}$ onto clinoptilolite particles
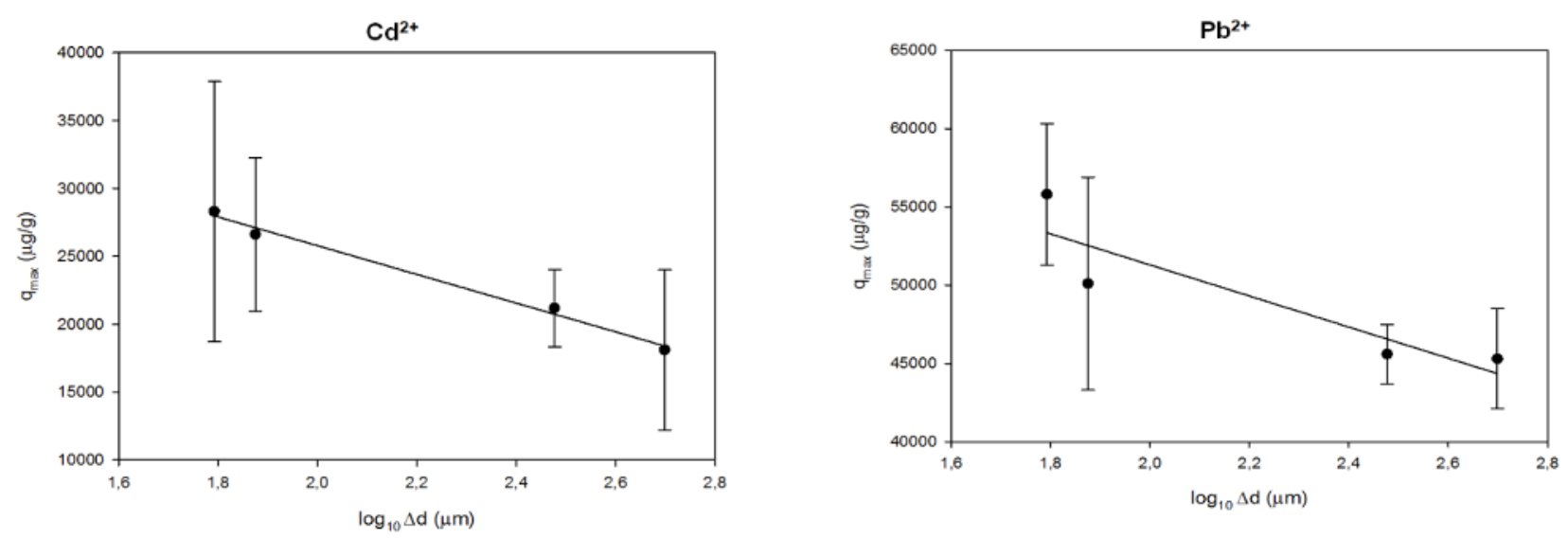

Fig.4 Linear dependence of $\mathrm{Pb}^{2+}$ and $\mathrm{Cd}^{2+} \mathrm{q}_{\max }$ from clinoptilolite size particles

A linear dependence of the adsorption constant rate from the particle size was found for both metals. Even thought this dependence need further verification, due to the few available data and the high associated error, the slope is lower than expected. 240 minutes $\mathrm{Pb}$ and $\mathrm{Cd}$ reach up the steady state, demonstrating a fast attainment of equilibrium.

The knowledge of equilibrium time allowed the successive study of thermodynamic aspects, in particular the study of adsorption isotherms at each range diameter particle. Figure 3 shows the adsorption isotherm of $\mathrm{Cd}^{2+}$ (left panel) and $\mathrm{Pb}^{2+}$ (right panel) onto clinoptilolite. It can be seen that these two metal elements have a different behavior and different adsorption properties.

The data concerning adsorption of $\mathrm{Cd}^{2+}$ onto clinoptilolite were well-fitted by Langmuir isotherm, while for $\mathrm{Pb}^{2+}$ the best fitting was obtained by the Sips isotherm model. These differences in the type of isotherm suggest a different mechanism of adsorption of these two metals. For $\mathrm{Cd}^{2+}$ the prevalent mechanism is probably the ion exchange that involves the coverage of the solid surface with a monolayer of ions as to predict by Langmuir isotherm. On the other hand, for $\mathrm{Pb}^{2+}$ the Sips isotherm suggest a degree of heterogeneity in the adsorption process (Duong D.Do, 1998), probably due to the presence of several $\mathrm{Pb}^{2+}$ chemical species: it is possible that $\mathrm{Pb}^{2+}$ is able to adsorb onto clinoptilolite not only by ion exchange but also by complex formation with the free -OH groups present at the solid surface (Canepari et al., 1998).

Figure 4 reports the variation of the maximum amount $\left(\mathrm{q}_{\max }\right)$ of adsorbed metal in dependence of the particle size $\left(\log _{10} \Delta d\right)$. A linear dependence of the maximum amount of adsorbed metal with size diameter particles can be evidenced; as expected large amounts of ions can be adsorbed on particles with low diameters. However, considering these data is evident as the difference between the $\mathrm{q}_{\max }$ on small and large particles is not as large as expected. This aspect is also confirmed by the low value of the slope of the two fitting straight line. Lastly, it is worth noting that $\mathrm{q}_{\max }$ values are always larger for $\mathrm{Pb}^{2+}$ than for $\mathrm{Cd}^{2+}$ regardless of the dimensional range. This result confirm the hypothesis of a combined mechanism for $\mathrm{Pb}^{2+}$ adsorption, which determines an amount of adsorbed ion larger than the one retained by the ion exchange mechanism. 


\section{Conclusion}

Size dimension of particles seems to scarcely influence the heavy metal removal performances of clinoptilolite. This result is very interesting, as the linear dependence of $\mathrm{q}_{\max }$ and $\mathrm{k}_{\mathrm{obs}}$ constant from particle sizes, could be applied for an easier optimization of the parameters in field site remediation.

In the future we will deepen the influence of the ionic strength (up to the seawater level) on the adsorption of $\mathrm{Cd}, \mathrm{Pb}$ and $\mathrm{Ni}$ to evaluate possible applications of clinoptilolite to a remediation of refinery's coastal groundwater.

\section{Acknowledgements}

We want to thank Dott.ssa Maria Luisa Astolfi for her precious advices and Riccardo Fiorentino.

\section{References}

Canepari S., Carunchio V., Castellano P., Messina A. Complex formation equilibria of some b-aminoalcohols with lead(II) and cadmium(II) in aqueous solution. Talanta 47 (1998) 1077-1084.

Duong D.Do. Adsorption analysis: equilibria and kinetics. Department of Chemical Engineering University of Queensland. Queensland, Australia. ISO 11260:1994 - Soil quality - Determination of effective cation exchange capacity and base saturation level using barium chloride solution.

Uzoekwe, S. A. and Oghosanine, F.A. the effect of refinery and petrochemical effluent on water quality of Ubeji Creek Warri, Southern Nigeria. Ethiopian Journal of Environmental Studies and Management Vol. 4 No.2 2011. 